\title{
Assessing locomotion deficiency in broiler chicken
} \author{
Almeida ${ }^{5}$; Anderson Luiz de Souza ${ }^{1}$ \\ ${ }^{1}$ UNICAMP/FEAGRI, C.P. 6011 - 13083-970 - Campinas, SP - Brasil. \\ ${ }^{2} U F G D / F C A$, C.P. 322 - 79825-070 - Dourados, MS - Brasil. \\ ${ }^{3}$ UNICAMP/FEAGRI - Programa de Pós Graduação em Engenharia Agrícola. \\ ${ }^{4} U N I P / E P$, R. Dr. Bacelar, 1212 - 04026-002 - São Paulo, SP - Brasil. \\ ${ }^{5} U N E S P / F M V Z$, C.P. 502 - 18618-000 - Botucatu, SP - Brasil. \\ *Corresponding author <irenilza@feagri.unicamp.br>
}

Irenilza de Alencar Nääs ${ }^{1 *}$; Ibiara Correia de Lima Almeida Paz ${ }^{2}$; Marta dos Santos Baracho ${ }^{1}$; Adriana Gomes de Menezes ${ }^{3}$; Karla Andrea Oliveira de Lima ${ }^{3}$; Leda Gobbo de Freitas Bueno ${ }^{3}$; Mario Mollo Neto ${ }^{4}$; Victor Ciaco de Carvalho ${ }^{1}$; Ianê Correia de Lima

\begin{abstract}
Locomotion deficiencies in broiler production cause poor welfare and lead to change in drinking and feeding behavior with consequent loss in weight gain. This research aimed to assess locomotion deficiencies in broiler chicken by analyzing the vertical peak force on both feet during walk. A chamber was built with an inlet ramp, a horizontal walkway in the middle and an outlet ramp. In the walkway a thin mat with piezoelectric crystal sensors was placed to record the step vertical peak force of the feet while walking on the force platform. The measurement system consisted of a mat with electronic sensors and software that allowed real time recording of the forces and the processing and analysis of data. Footage was taken from two digital video cameras and used for gait scoring. Forty male broilers were chosen at random, grown under similar rearing conditions and farms, with age varying from 49 to 28 days (ten birds of same age) to be used in the trial. Measurement consisted of inducing the bird to walk on the force platform which automatically registered the peak vertical force of the steps. Results showed that the gait score increased with the weight and age of the birds. Peak force asymmetry was found for each foot, independent of age or gait score. Although not identified visually in the broilers, the peak vertical force values differed in both right and left feet leading to slow and uneven walking. Walking deficiency was more severe in older birds.
\end{abstract}

Key words: poultry production, gait scoring, feet force measurement, welfare

\section{Medida de deficiência locomotora em frango de corte}

\begin{abstract}
RESUMO: Deficiência em locomoção é hoje um dos problemas mais importantes na produção de frangos de corte. É causa de baixo bem-estar e leva a alteração no comportamento de bebida e alimentação, com conseqüente perda de ganho de peso. Mediram-se deficiências locomotoras em frango de corte por meio da análise do pico de força plantar vertical em ambas as patas, durante a caminhada. Foi construída uma câmara com uma rampa de entrada, uma área horizontal de passagem e uma rampa de saída. Na parte horizontal da área de passagem foi colocado um tapete fino, com elementos sensores de cristal piezoelétrico, para registrar o pico de força vertical das patas do frango quando este caminhava sobre a plataforma. O sistema de mensuração consistiu de um tapete com sensores eletrônicos e um programa computacional que permitiu o registro de forças em tempo real e o processamento e a análise de dados. Imagens de vídeo foram tomadas a partir de duas câmeras digitais para atribuir o gait score. Quarenta frangos machos foram aleatoriamente selecionados em condições similares de alojamento e da mesma granja, com idade variando de 49 a 28 dias (dez de cada idade) e usados no experimento. A medida consistiu em induzir a ave a caminhar sobre a plataforma de força que automaticamente registrava o pico de força da passada. O gait score aumentou com o peso e a idade das aves. Foi encontrada assimetria nos picos de força da cada pata, independente da idade ou gait score. Embora não tenha sido identificado visualmente nos frangos, o pico de força vertical é diferente tanto na pata direita quanto na esquerda, levando a um caminhar lento e desigual. A deficiência locomotora foi mais intensa em aves mais velhas.

Palavras-chave: produção de frangos de corte, medida de locomoção, medida de pressão plantar, bem-estar
\end{abstract}

\section{Introduction}

Leg disorder is one of the causes of poor welfare in broiler chickens leading to locomotion difficulties and degenerative diseases (Bizeray et al., 2000; Boersma, 2001; Butterworth, 1999; SCAHAW, 2000). There are large differences in walking ability, as well as in some impor- tant traits associated with leg weakness, between chicken commercial line crosses (Kestin et al., 1999). Age, gender, weight gain and growth rate were also found to be related to lameness (Kestin et al., 2001), and lower stocking density substantially reduced the prevalence of leg weakness (Sorensen et al., 2000). One of the major consequences of locomotion deficiency is related to the 
change in drinking and feeding behavior leading to loss in weight gain (Weeks et al., 2000; Savory and Kostal, 2006). Danbury et al. (2000) studied the walking ability of lame broilers and found that trained birds selected more analgesic supplemented feed when the severity of the lameness increased, indicating that lame broiler might feel pain.

The gait scoring system for broilers developed by Kestin et al. (1992) has been widely used to evaluate leg problems. The methodology consists of an empirical observation of locomotion factors with a risk of poor test reliability. Garner et al. (2002) and Weeks et al. (2002) developed a modified gait score system; however, it also relies on the individual observation and evaluation being therefore also inaccurate.

When the animal walks it generates a specific pressure over the floor that is a function of its weight, as well as the way it lays the feet/claws over that surface. The energy involved in locomotion, as well the influence of the center of mass on the ground reaction forces produced by birds during walking altering both kinetic data (e.g., ground reaction forces) and kinematic data (e.g., stance and stride durations) are well documented in literature (Corr et al., 1998; Fedak et al., 1982; Muir and Chu, 2002; Muir and Gowri, 2005; Roberts et al., 1997). Corr et al. (1998) used a pedobarograph system which consisted of deflection of light scattered onto a float glass plate captured by a video camera to evaluate pressure distribution under the claw of poultry. A sheet of unexposed, processed photographic paper was placed on the upper surface of the float glass with the emulsion downward. When pressure is exerted on the surface of the paper the emulsion layer is pressed into a closer contact with the glass producing scattering of light which can be viewed from underneath the glass and captured by a camera. The system was synchronized with four load cells on each corner of the plate to yield vertical ground reaction forces and enable calibration of dynamic applied pressures. Carvalho et al. (2005) used a technology developed by the Massachusetts Institute of Technology (MIT) that consisted of a thin mat housing arrays of piezoelectric sensors for determining the force and pressure distribution in dairy cow claws and found the precise points with higher pressures, which helped claws trimming management in commercial dairy farms. The advancement in information technology made the assessment possible of applied ground reaction forces and pressures more efficiently and with advantages of real time calibration and portability as compared to the pedobarograph used in previous studies (Corr et al., 1998).

This research aimed to assessing locomotion deficiencies in broiler chicken of different ages by analyzing the vertical peak force on both feet during walking.

\section{Material and Methods}

A chamber was built using transparent acrylic walls with dimensions of $0.48 \mathrm{~m}$ width, $0.70 \mathrm{~m}$ height and $1 \mathrm{~m}$ length, with an inlet ramp of $0.20 \mathrm{~m}$, a horizontal plateau of $0.60 \mathrm{~m}$ in the middle and an outlet ramp of 0.20 $\mathrm{m}$. Both inlet and outlet ramps had an angle of five degrees in relation to the floor (Figure 1a). On the horizontal plateau of the walking area (Figure 1a) a $0.01 \mathrm{~m}$ step was carved in which a thin mat was placed that incorporated piezoelectric crystal sensing elements, so called sensels (MatScan, Tekscan ${ }^{\circledR}$ Inc) for measuring and registering the walking forces of both feet of the broilers while they walked across the section (Figure 1b).

The pressure measurement system consisted of two parts: the hardware (pressure mat) that recorded the force data and transferred them to the software, and the software that allowed recording an image visualization of the forces and processing and analysis of data. The electronic mat hardware is formed by nearly two thousands piezoelectric sensels organized in columns and lines which can be defined as micro, liquid based, strain gages (Tekscan ${ }^{\circledR}$ Inc. patented technology - 125 PSI saturation pressure) that produce a deflection when loaded, that is translated into voltages similar to a load cell. Therefore, the sensels loaded in a trial can be summed to produce the total applied force. The output of each sensel was divided into 256 increments, and read by the software in values called "raw sum" ranging from 0 to 255. The software was installed in a computer, and converted the captured values into a pressure map that could be seen in distinct colors in real time, or saved for further analysis. The color scale ranged from dark blue (low pressure) to dark red (high pressure).

Video footage was taken from two digital cameras (JVC GDR-120U - 30 Hz. 520 lines vertical resolution) for gait scoring. The first camera was placed at a distance of approximately $1.0 \mathrm{~m}$ aside from the plane of motion (wooden platform with the pressure system section used for plantar pressure data collection), as suggested by Carvalho et al. (2005). The second one was placed over the middle of the walking platform attached to a pole $1.3 \mathrm{~m}$ high. Both video cameras working at the speed of 30 frames $\mathrm{s}^{-1}$ ) were aligned on its vertical and horizontal axis, and at a $90^{\circ}$ angle from the plane of motion and were used to record sagital and transversal planes kinematics. Kinematics has been used in experiments involving mechanisms of terrestrial locomotion and to visually assess gait abnormalities. Gait analysis can be very useful to find discrete walking impairments by visually observing gait in a frame by frame basis; however, it is subjective and cannot be quantified. Quantification of gait can be made by calculating kinematic parameters such as linear walking velocity, acceleration, stride and step length and most importantly angular parameters including angular velocities, accelerations and angular range of motion (ROM) of joints and therefore characterizing observational gait analysis quantitatively allowing the comparison among sample populations.

Forty male broilers at 28, 35, 42, and 49 days of age (10 of each age) from the same genetic strain $\left(\mathrm{Cobb}^{\circ} 500\right)$ were randomly chosen at a commercial poultry farm, 
a)

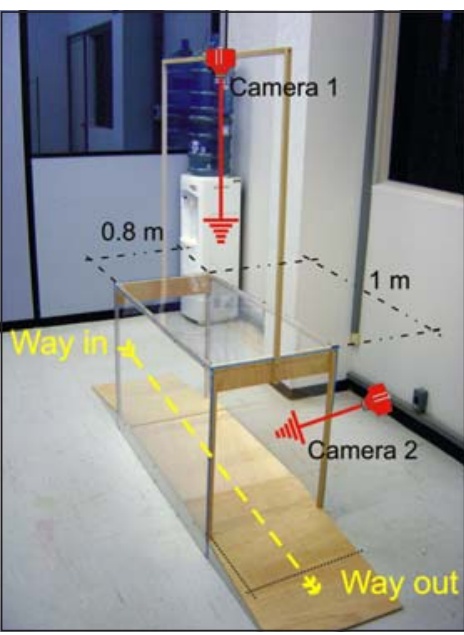

b)

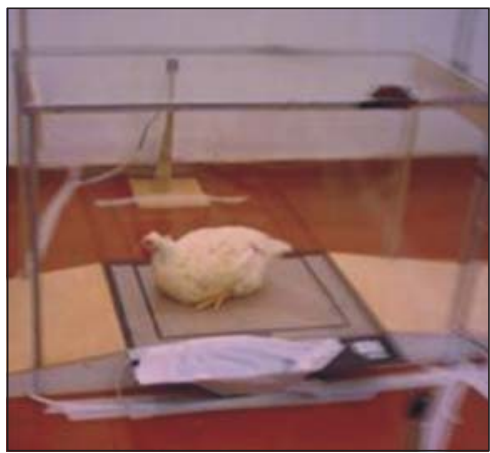

Figure 1 - Runway chamber (a) and the broiler feet pressure measurement apparatus and the video cameras recording the bird movement (b).

that had several broiler houses rearing birds at distinct ages, and at an average stocking density of 13 birds per $\mathrm{m}^{2}$. They were transported in boxes for $35 \mathrm{~km}$ to the laboratory and used in the trial. Immediately upon arrival at the experimental site, the birds rested for $40 \mathrm{~min}$ and were given water. Each bird was assigned a number and it was colored on its head with an animal mark coat for individual recognition. The birds were weighed and then separated by age and put in boxes. The experiment started with the older birds. The laboratory had a controlled environment area with ambient temperature set at $25^{\circ} \mathrm{C}$.

A gait score was given to each bird using the scale 5 to $O(5=$ lame bird; $O=$ sound bird $)$ as proposed by Kestin et al. (1992), by a trained person after watching both pieces of footage. The images from the video recording over the middle of the runway gave information on the alignment of the bird walking, while the lateral images showed the leg displacement. The locomotion measurement consisted of inducing the bird to walk on the platform and automatically registering the force data of both feet separately. The analysis used the results for comparing the Maximum Ground Reaction Forces (MaxGRF) of both feet and the time the bird took to walk on the $1 \mathrm{~m}$ section, as well as the gait score values. The MaxGRF are displayed taking into account all the piezoelectric sensels loaded within the step area in a given frame whereas peak ground reaction forces (PeakGRF) are displayed by the software by pointing the sensel with the highest value of the ground reaction force obtained among all of the sensels within the step area of a specific frame. As MaxGRF over a run always exceeded bodyweight it was adjusted by first subtracting bodyweight before being expressed as a percentage (Corr et al., 1998; Carvalho et al., 2005; Corr et al., 2007). The spatial and temporal integration of force data over a step are included by the synchronization of force and kinematics equipment used, the cameras and the pressure mat adjusted to work at the same speed.

All analyses were performed using the statistical software MINITAB ${ }^{\varpi}$ (MINITAB, 2006). The data were analyzed using ANOVA for the registered variables to verify the variability between and within groups, using a confidence interval of $95 \%$.

\section{Results and Discussion}

The hypothesis under analysis was that the gait patterns produced by rapidly growing broilers are influenced primarily by the resulting forces during walking due to changes in body conformation proportional to the age. The results are shown in two ways, first the gait visual observation of selected birds, and then the electronic measured forces involved in the displacement process.

\section{Bird weight and gait score}

The weight of the 49, 42, 35 and 28 days old broilers (Figure 2) was $3054.0 \pm 2.2 \mathrm{~g}, 3000.0 \pm 159.13 \mathrm{~g}, 2431.50$ $\pm 100.94 \mathrm{~g}$, and $1411.5 \pm 100.9 \mathrm{~g}$, respectively. Older and heavier birds presented more walking difficulties and were given higher gait score (Figure 3). A similar result was found by Soerensen et al. (2000), who concluded that at 28 days locomotion disorders was a relatively minor problem; and few severely lame birds had a gait score of 4 or 5 . However, the birds 42 days old had substantially poorer walking ability while further deterioration was present in broilers 49 days old. All birds walked on the force measurement apparatus, but only 11 birds successfully crossed the walkway in a continuous manner

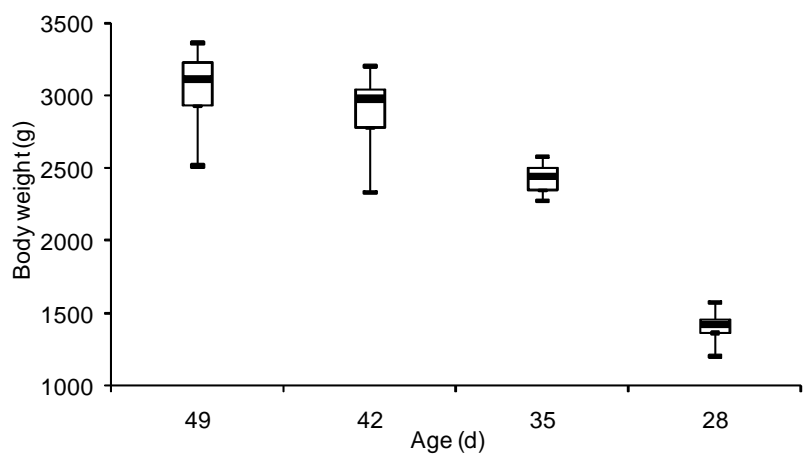

Figure 2 - Boxplot of the broilers used in the trial average weight from 49 to 28 days old distributed in four weight classes (49, 42, 35 and 28). 
allowing the full registration of foot force data, two being from the age class $49 \mathrm{~d}$, three from $42 \mathrm{~d}$, two from 35 $\mathrm{d}$ and four from the class of 28 days old. The use of small number of birds in walking behaviour trials was accepted in previous studies using operant walkway or modeling dynamic activities for broiler chicken (Bokkers et al, 2007; Corr et al., 1998; Corr et al., 2007; Weeks et al., 2000). The pressure and equivalent MaxGRF was made with the broilers that walked continuously on the platform from the inlet towards the outlet.

Kestin et al. (1999) studied the differences between genotypes and broiler walking ability and found differences among genotypes with respect to the correlation coefficients between walking ability and body weight; walking ability and hock burn, as well as tibial dyschondroplasia and body weight. It was found that broiler locomotion ability tends to decrease as body weight increases.

Results on the birds walking pressure and MaxGRF exerted by each foot were selected from broilers with gait score from 4 to 1 , as none of the sound birds were found in the tested group (Figures 4 to 7 ) and is shown in one set of results chosen randomly for each given gait score. A severely lame bird (gait score 4) laid down often on the pressure measurement walkway, and the software output was an image with the whole body and the feet on the platform (Figure $4 \mathrm{a}, \mathrm{b}$ ). Bird number 7 laid down for $60 \mathrm{~s}$ and walked for $20 \mathrm{~s}$ (Figure $4 \mathrm{c}$ ). According to Weeks et al. (2000) lameness, with its associated disability and probable pain, significantly increases the time spent lying. Selection for high breast meat yield has moved foreward the centre of gravity of the broilers, which may unbalance them and predispose them to sitting behavior (Weeks et al., 2000). It is also likely that the lying position is the most comfortable and least physically demanding posture for a bird with leg problems (Bizeray et al., 2004). Similar results were found in this trial as lame birds walked on the platform. When moving the vertical peak force of the feet of bird number 7 was over the distal position of the middle toe of the left foot (Figure $4 \mathrm{~b}$ ).

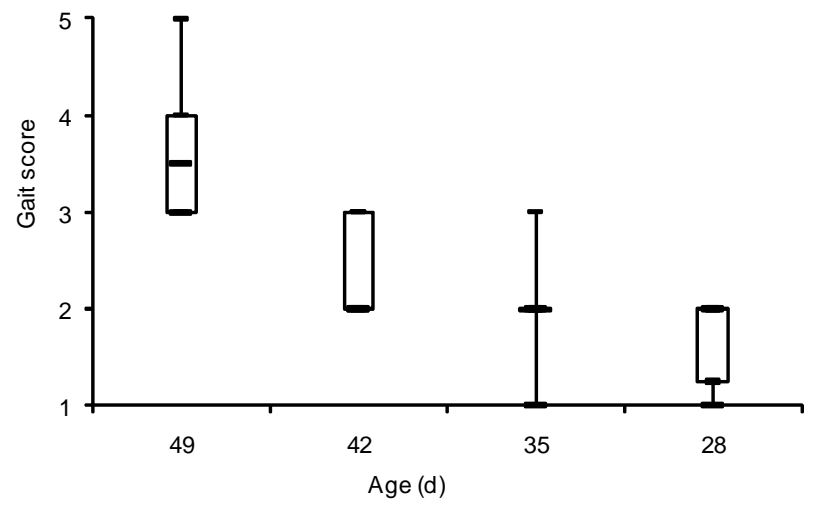

Figure 3 - Boxplot graph of the gait score variation within the broilers used in the trial from 49 to 28 days old using four classes of age (49, 42, 35 and 28).
The walking force results of bird number 19 with gait score 3 (Figure 5a) showed that the MaxGRF in both feet were high, and their distribution was found to be asymmetric, and out centered in the right foot (Figure 5b). Bird spent over $60 \mathrm{~s}$ walking on the platform with a slow and constant movement (Figure 5c). Both birds (7 and 19) presented low speed during walking. Lame birds tend to walk slower than sound ones, as there are biomechanical advantages in adopting slower speeds. This walking pattern reduces the MaxGRF, and therefore the stresses on the musculoskeletal system that is produced during walking (Corr et al., 1998; Corr et al., 2007; Fedak et al., 1982).

Lame birds with gait scores 3 to 4 are more severely disabled than sound birds and are heavier as well (Kestin et al., 1992; 2001). In a field study, Kestin et al. (1992) found that the welfare of $19 \%$ of the birds with gait score 3 was compromised as a result of leg weakness; the authors stressed that there was likely to be chronic pain and also discomfort for these birds. As unsound birds need a certain degree of motivation for walking, in this experiment the fact that may have motivated the moving of broiler number 19 could be a drinker put at the end of the platform, and the bird could have been thirsty and tried to reach the water.

Figure 6a shows the software image output of the feet pressure distribution and the MaxGRF points for bird number 34 with a gait score 2. The MaxGRF is concentrated in few points in the rear part of the feet (metatarsal pad and back toe). The bird moved faster in the first $10 \mathrm{~s}\left(0.1 \mathrm{~m} \mathrm{~s}^{-1}\right)$, and there was a large variation in the MaxGRF exerted on the walkway, meaning that the bird had a distinct way of stepping on the force platform (Figure 6c). The MaxGRF was not homogeneously distributed, with the right foot applying more pressure than the left one (Figure $6 \mathrm{~b}$ and Table 1). This was not evident by visual observation of bird number 34 which had a gait score of 2, as it walked without much difficulty on the platform, even though the MaxGRF output was centered in the metatarsal pad and back toe (Figure 6b).

Gait scores from 3 to 5 are considerably undesirable in the UK, Sweden and many other European countries; however, Grandin (2007) suggests a flock acceptable gait score standard when $95 \%$ of the birds can walk evenly for ten steps. Under this pattern the bird number 34 with gait score 2 could be classified as having an acceptable gait score.

The software image output of bird number 30 with gait score 1 presents uneven distribution of MaxGRF (Figure $a, b)$, and the left foot carried the heavier load (Table 1). The bird moved fast on the platform during the first $15 \mathrm{~s}\left(0.06 \mathrm{~m} \mathrm{~s}^{-1}\right)$ (Figure 7c). The broiler walking in an even way may be an indication of good welfare (Manning et al., 2007). In this experiment the MaxGRF asymmetric shows that the birds with low gait score presented an uneven use of both legs/feet, even though this walking condition could not be detected in the footage during their walking and gait scoring. Broilers with gait 
score 1 and 2 had a walking speed nearly twice as fast as the ones with gait score 3 and 4, which agrees with the results of Sorensen et al. (2000) who found that lame birds spend $50 \%$ less time standing or in walking activities, when compared to sound birds.

Normal gait conserves both kinetic and potential energy and follows the principle of biological conservation of energy. Adaptations of gait in unsound animals (reported as presenting gait score from 3 to 5) often cause rotations of feet and every articulation which will have consequences for the skeletal system, creating a progressive and degenerative problems that may lead to pain (Butterworth, 1999; Resch-Magras et al., 1993; Weeks et al., 2000).
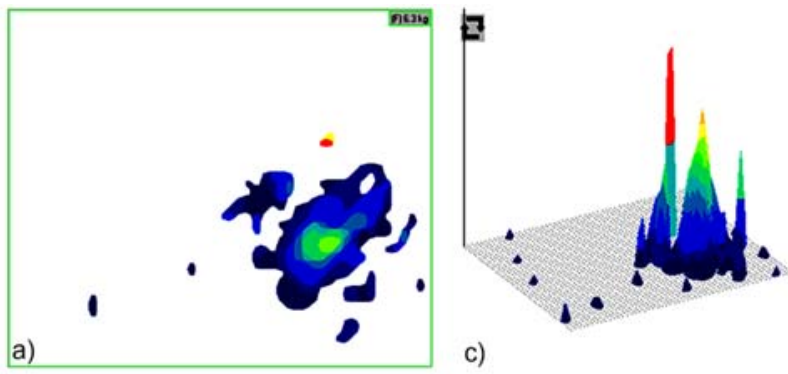

c)

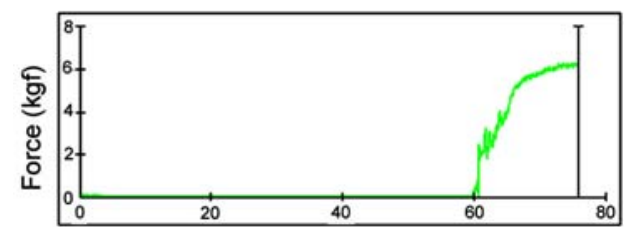

b)

Time (s)

Figure 4 - Image of the walking pressure resultant from bird number 7 with gait score 4 (a), software output of the equivalent MaxGRF display in three dimensions (b), and its distribution during locomotion (c).
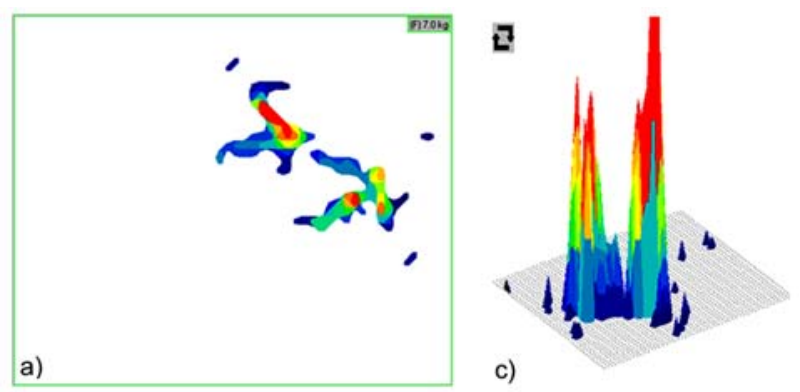

c)

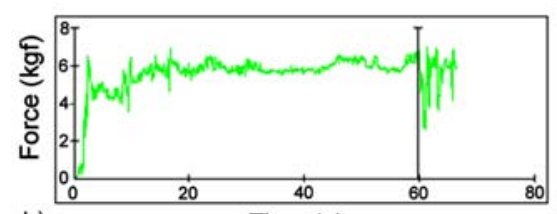

b)

Time (s)

Figure 5 - Image of the walking pressure resultant from bird number 19 with gait score 3 (a), software output of the equivalent MaxGRF display in three dimensions (b), and its distribution during locomotion (c).
During the trial it was not possible to visually accurately distinguish whether older broilers prefer to lie down or present lameness. It was also difficult to identify birds that appeared to walk well or with only a slight impairment of gait (e.g. gait score 1), or yet those between moderate and substantial lameness (e.g. gait score 2 and 3$)$.

\section{Force on feet during walking}

For the analysis of the force exerted by both feet during walking an individual step was analyzed for all birds, as it was considered acceptable in a previous study (Corr et al., 2007). Software output mean data from both right and left feet MaxGRF during the step phase from all broilers in the trial is shown in Figure 8. This varied for
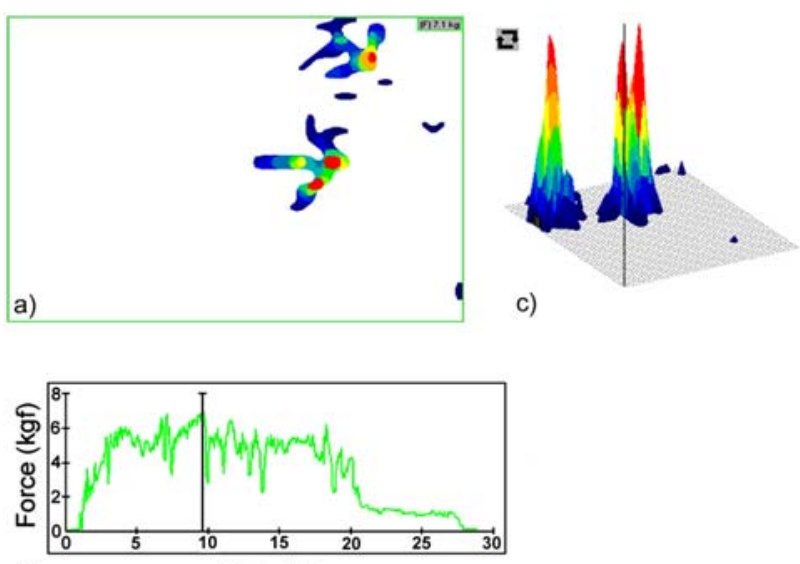

b)

Time (s)

Figure 6 - Image of the walking pressure resultant from bird number 34 with gait score 2 (a), software output of the equivalent MaxGRF display in three dimensions (b), and its distribution during locomotion (c).
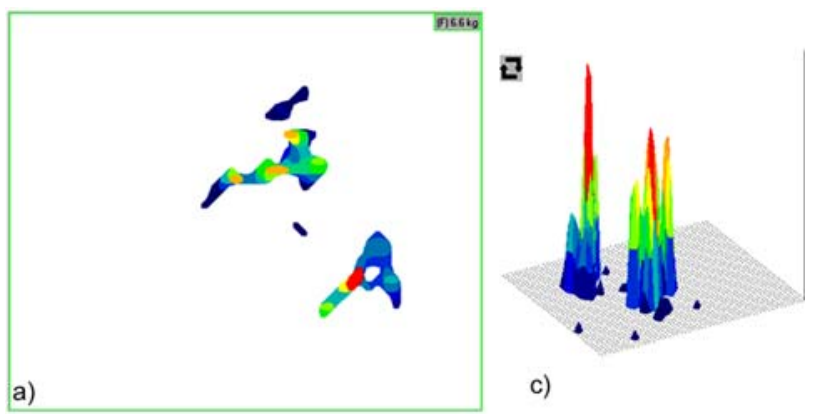

c)

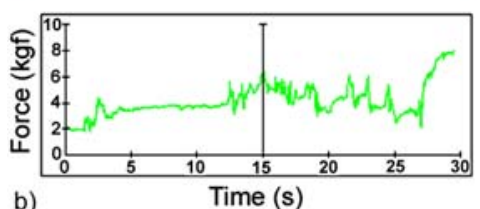

Figure 7 - Image of the walking pressure resultant from bird number 30 with gait score 1 (a), software output of the equivalent MaxGRF display in three dimensions (b), and its distribution during locomotion (c). 


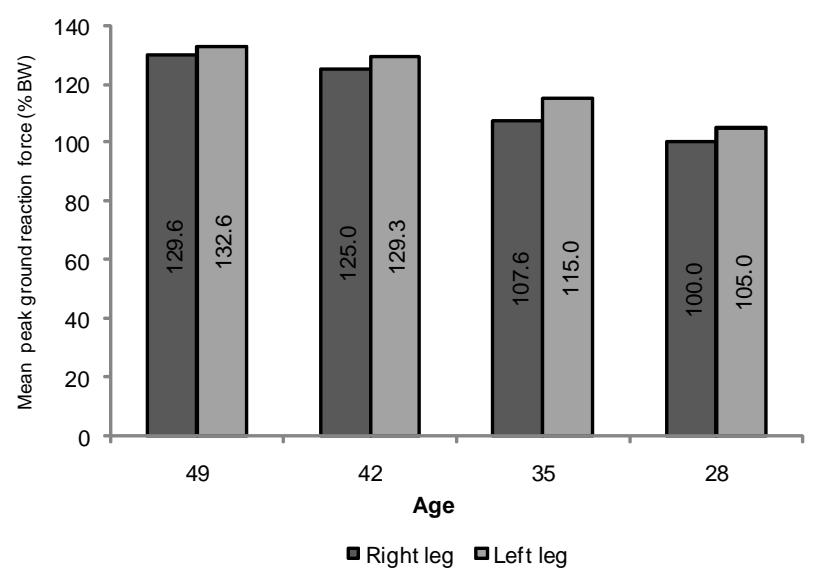

Figure 8 - Mean MaxGRF distribution of broilers ranging from 49 to 28 days old as percentage of their body weight, during the trial to test locomotion deficiency using a platform system measurement.

all broilers in the trial although maintaining a trend for each age class. It seems that although not seen clearly by visual observation, the broilers walked unevenly, and showed increasing lameness condition during growth (Resch-Magras et al., 1993; Muir et al., 1996).

MaxGRF values recorded were similar to those found by Corr et al. (2007) in a study using a force platform associated to video image analysis. When comparing the force output values for the sample of specific birds, in the software output image, it was clear that the selected broilers presented distinct values of MaxGRF distribution on both feet, which causes the birds to be unbalanced when walking and may be associated to leg lesions (Table 1). However, this was not visually noticed in birds with gait score 2 or 1 , making it difficult to determine whether they were suffering due to lameness.

Studying locomotory deficiencies in turkeys ReschMagras et al. (1993) found that some leg conditions can create asymmetry in walking forces that may impact asymmetrical bone development in each leg. Asymmetrical bone development is compensated by asymmetric gait which can cause lameness. Thus the asymmetry in MaxGRF in both right and left feet detected in this experiment may indicate some degree of lameness, although it was not still visually detected in young broilers (Muir and Chu, 2002). Walking ability is lower in fast-growing birds, independently of diet or management, and abnormal behavior related to this actually starts in a very early stage in life (Muir et al., 1996). To start walking, an animal must produce forward-oriented ground reaction forces while still maintaining balance and reasonable joint moments. Roberts and Scales (2002) studied the ground forces reaction related to turkey running, and using the limb kinematics observed that during a steady-speed run and a high acceleration the birds would experience a certain twist of the center of mass that would tend to pitch the body about a transverse axis $\left(300^{\circ}\right.$ of body rotation in $200 \mathrm{~m}$ ). Roberts and Scales (2002) reported that, in the absence of alignment of the ground reaction force and the center of mass, the propulsive forces produced by an accelerating turkey would be sufficient to produce nearly a full backward rotation of the body in a single foot-floor contact period. It is likely that extra energy input is needed for balancing the center of mass in the lack of alignment.

No difference $(\alpha>0.05)$ was found in the peak GRF in both right and left feet for all the birds with gait score 2 and 1; however, broilers of all ages presented some degree of asymmetric peak GRF. Older and heavier birds tend to compensate for walking difficulties by using the legs in an unbalanced way for minimizing eventual discomfort or pain (Bizeray et al., 2000; Butterworth, 1999; Danbury et al., 2000). The peak GRF increased positively with age as expected, showing a positive correlation with the gait score for the selected birds. Ground reaction force is equal in magnitude and opposite in direction to the force that the body exerts on the supporting surface through the foot. Unbalanced pattern of force may contribute to the lack of alignment of the center of mass during stance, and a change in the magnitude of the force means that the angle from the vertical ground reaction force for any given propulsive force is either smaller or larger, contributing to the unbalance of the body (Roberts et al., 1997).

Most of the muscle activity and force production occurred during stance, when force must be produced to support animal weight and work must be done to lift and reaccelerate the body. The decrease in kinetic energy that occurs as the animal slows during one part of the step while walking is stored in gravitational energy as the center of mass rises (Fedak et al., 1982). This stored energy is recovered in the step as the animal moves and the center of mass falls down. This balanced mechanism, similar to an inverted pendulum is energysaving, and is proportional to the moving speed when the peak vertical forces are equally distributed in both legs. When the peak vertical forces in the right and left foot are unbalanced, this pendulum mechanism is deprived requiring more energy during walking. This trade-off between energy input and force output indicates that animals could minimize the cost of producing force during the movement by operating proper muscles that produce force while minimizing mechanical work (Roberts et al., 1997).

\section{Conclusions}

The electronic measurement system used in this research allowed assessing in real time the peak vertical force made by the broilers with their feet while walking. The output showed their asymmetric movement, as the birds weight was not evenly distributed in both feet during locomotion. The gait patterns of rapidly growing broilers may be influenced by the asymmetric vertical peak force in both feet at all ages.

The current experiment characterized gait in an observational basis aided by forces obtained using a high technology piezoelectric sensing apparatus. Further ad- 
Table 1 - Data on MaxGRF (\% of body weight, BW) in both right and left feet, the given gait score and the total displacement time on the walkway of the selected broilers.

\begin{tabular}{lcccc}
\hline \multirow{2}{*}{$\begin{array}{l}\text { Broiler number and age } \\
\text { \# (days) }\end{array}$} & \multicolumn{2}{c}{ MaxGRF \% BW } & Gait score & \multicolumn{2}{c}{ Total displacement time } \\
\cline { 2 - 3 } & Right foot & Left foot & & 7 \\
\hline $7(49)$ & - & - & 3 & 76 \\
$19(42)$ & 119.8 & 106.9 & 36 \\
$34(35)$ & 104.4 & 105.5 & 2 & 27 \\
$30(28)$ & 90.2 & 98.0 & 1 & 30 \\
\hline
\end{tabular}

vancements using appropriate thresholds may allow developing an algorithm for calibrating the visual gait scoring. The quantification of gait analysis is a next step to characterize gait in further experiments and will strengthen the estimation proposed.

\section{Acknowledgement}

To CNPq for the research grant.

\section{References}

Bizeray, D.; Laterrier, C.; Constantin, P.; Picard, M.; Faure, J.M. 2000. Early locomotor behaviour in genetic stocks of chickens with different growth rates. Applied Animal Behaviour Science 68: 231-242.

Bizeray, D; Faure, J.M.; Leterrier, C. 2004. Faire marcher lê poulet: pourquoi et comment. INRA Producion Animale 17: 45-57.

Boersma, S. 2001. Managing rapid growth rate in broilers. World Poultry 17: 28-29.

Bokkers, E.A.M.; Zimmerman, P.H.T.; Rodenburg, B.; Koene, P. 2007. Walking behaviour of heavy and light broilers in an operant runway test with varying durations of feed deprivation and feed access. Applied Animal Behaviour Science 108: 129-142.

Butterworth, A. 1999. Infectious components of broiler lameness: a review. World's Poultry Science Journal 55: 327-352.

Carvalho, V.R.C.; Bucklin, R.A.; Shearer, J.K.; Shearer, L. 2005. Effects of trimming on dairy cattle hoof weight bearing and pressure distributions during the stance phase. Transactions of the ASAE 48: 1653-1659.

Corr, S.A.; McCorquodale, C.C.; Gentle, M.J. 1998. Gait analysis of poultry. Research in Veterinary Science 65: 233-238.

Corr, S.A.; McCorquodale, C.M.; Mcdonald, J.; Gentle, M.; Mcgovern, R. 2007. A force plate study of avian gait. Journal of Biomechanics 40: 2037-2043.

Danbury, T.C.; Weeks C.A.; Chambers, J.P.; Waterman-Pearson, A.E.; Kestin S.C. 2000. Self-selection of the analgesic drug carprofen by lame broiler chickens. Veterinary Record 146: 307-311.

Fedak, M.A.; Helung, N.C.; Taylor, C.R. 1982. Energetics and mechanics of terrestrial locomotion. II. Kinetics energy changes of the limbs and body as function of body size in birds and mammals. Journal of Experimental Biology 79: 23-40.

Garner, J.P.; Falcone, C.; Wakenell P.; Martin, M.; Mench, J.A. 2002. Reliability and validity of a modified gait scoring system and its use in assessing tibial dyschondroplasia in broilers. British Poultry Science 43: 355-363.

Grandin, T. 2007. Poultry Slaughter Plant and Farm Audit: Critical Control Points for Bird Welfare. Available at: http// www.grandin.com/poultry.audit.html. [Accessed Jan.12, 2008]
Kestin, S.C.; Knowles, T.G.; Tinch, A.E.; Gregory, N.G. 1992. Prevalence of leg weakness in broiler chickens and its relationship with genotype. Veterinary Record 131: 190-194.

Kestin, S.C.; Su, G.; Sorensen, P. 1999. Different commercial broiler crosses have different susceptibilities to leg weakness. Poultry Science 78: 1085-1090.

Kestin, S.C; Gordon, S.; Su, G.; Sorensen, P. 2001. Relationships in broiler chickens between lameness, liveweight, growth rate and age. Veterinary Record 148: 195-197.

Minitab. 2006. Minitab 15.1.0.0. Minitab, State College, TX, USA.

Manning, L.; Chadd, S.A; Baines, R.N. 2007. Key health and welfare indicators for broiler production. World's Poultry Science Journal 63: 46-62.

Muir, G.D.; Gosline, J.M.; Steeves, J.D. 1996. Ontogeny of bipedal locomotion: walking and running in the chick. Journal of Physiology 493: 589-601.

Muir, G.D.; Chu, T.K. 2002. Posthatching locomotor experience alters locomotor development in chicks. Journal of Neurophysiology 88: 117-123.

Muir, G.D.; Gowri, K.S.V. 2005. Role of motor and visual experience during development of bipedal locomotion in chicks. Journal of Neurophysiology 94: 3691-3697.

Roberts, T.J.; Marsh, R.L.; Weyand, P.G.; Taylor, C.R. 1997. Muscular force in running turkeys: the economy of minimizing work. Science 275: 1113-1115.

Roberts, T.J.; Scales, J.A. 2002. Mechanical power output during running accelerations in wild turkeys. The Journal of Experimental Biology 205: 1485-1494.

Resch-Magras, C.; Chérel, Y.; Wyers, M.; Abourachid, A. 1993. Comparison between sound turkeys and turkeys with locomotor problems. Veterinary Research 24: 5-20.

Savory, J.C.; Kostal, L. 2006. Broiler breeder chickens show apparently abnormal behaviours when subjected to routine quantitative food restriction during rearing. Physiology \& Behaviour 88: 473-478.

Scientific Committee on Animal Health and Animal Welfare [SCAHAW]. 2000. The welfare of chickens kept for meat production (Broilers). European Commission, Health and Consumer Protection Directorate-General, Brussels, Belgium.

Sorensen, P.; Su, G.; Kestin, S.C. 2000. Effects of age and stocking density on leg weakness in broiler chickens. Poultry Science 79: 864-870.

Weeks, C.A.; Danbury, T.D.; Davies, H.C.; Hun, T.P.; Kestin, S.C. 2000. The behaviour of broiler chickens and its modification by lameness. Applied Animal Behaviour Science 67: 111-125.

Received February 18, 2008

Accepted January 05, 2010 